\title{
XENOTRASPLANTE RENAL CERDO hDAF-BABUINO. EXPERIENCIA Y REVISIÓN
}

\author{
M. GONZÁLEZ MARTÍN ${ }^{1}$, J. GARCÍA BUITRÓN ${ }^{2}$, A. ALONSO HERNÁNDEZ ${ }^{3}$, \\ A. CENTENO CORTÉS ${ }^{4}$, E. LÓPEZ PELÁEZ ${ }^{4}$, E. VÁZQUEZ MARTUL ${ }^{5}$, \\ J. MOSQUERA REBOREDO ${ }^{5}$, I. REQUEJO ISIDRO ${ }^{6}$, R. MÁÑEZ MENDILUCE 7
}

${ }^{1}$ Servicio de Urología. ${ }^{2}$ Coordinación de Trasplantes. ${ }^{3}$ Servicio de Nefrología. ${ }^{4}$ Unidad de Investigación.

${ }^{5}$ Servicio de Anatomía Patológica. ${ }^{6}$ Servicio de Radiodiagnóstico. ${ }^{7}$ Director Programa Xenotrasplante. Hospital Universitario Juan Canalejo. Fundación Barrié de la Maza. La Coruña.

Actas Urol Esp. 28 (3): 161-174, 2004

\section{RESUMEN}

XENOTRASPLANTE RENAL CERDO hDAF-BABUINO. EXPERIENCIA Y REVISIÓN

INTRODUCCIÓN: El xenotrasplante renal puede representar la solución a la creciente demanda de órganos. Presentamos nuestra experiencia y revisamos el estado actual del xenotrasplante.

MATERIAL Y MÉTODO: Hemos realizado 20 xenotrasplantes de riñón de cerdo transgénico hDAF a babuino con cuatro protocolos de inmunosupresión. Todos los receptores recibieron GAS 914.

Grupo A: Ciclofosfamida, Ciclosporina, Micofenolato y Corticosteroides $(n=10)$.

Grupo B: Ciclofosfamida, Ciclosporina, FTY 720 y Corticosteroides (n=3).

Grupo C: Basiliximab, Ciclosporina, FTY 720 y Corticosteroides $(n=3)$.

Grupo D: Basiliximab, FTY 720, Everolimus y Corticosteroides $(\mathrm{n}=4)$.

RESULTADOS: La supervivencia de los xenoinjertos osciló entre 1 y 31 días.

La supervivencia en relación con los protocolos de inmunosupresión no fue significativamente diferente: A) 7 días, B) 8 días, C) 8 días, D) 9 días.

CONCLUSIONES:

1. Los tiempos de isquemia fría influyen en la función inicial de los riñones, no en su evolución final.

2. El rechazo hiperagudo ha sido superado con la utilización de cerdos transgénicos, produciéndose el fracaso por rechazo humoral agudo, no controlado con los protocolos de inmunosupresión actuales.

3. Es preciso investigar y desarrollar otros protocolos de inmunosupresión que nos permitan un mejor conocimiento de la fisiología del xenoinjerto y de su potencial riesgo de transmisión de enfermedades.

PALABRAS CLAVE: Xenotrasplante. Babuino. Cerdo. Riñón.

\section{ABSTRACT}

RENAL XENOTRASPLANTATION OF HDAF PIG TO BABOONS. EXPERIENCE AND REVIEW

SUMMARY: The renal xenotrasplant could be the solution on the demand of organs for transplantation.

We present here our experience and review the actual status of the xenotransplant.

METHODS: We have done 20 xenotransplants from transgenic pig h DAF to baboons, with four protocols of inmunosupression. All the hosts were treated with GAS 914.

Group A: Cyclophosphamide, Cyclosporine, Mycophenolate, and Steroids ( $n=10)$.

Group B: Cyclophosphamide, Cyclosporine, FTY 720, and Steroids (n=3).

Group C: Basiliximab, Cyclosporine, Mycophenolate, and Steroids $(\mathrm{n}=3)$.

Group D: Basiliximab, FTY 720, Everolymus, and Steroids (n=4).

RESULTS: The duration of the xenografts ranged between 1 and 31 days.

The function of the xenografts in relation to the type of inmunosupression were not significantly different: A) 7 days, B) 8 days, C) 8 days, and D) 9 days.

CONCLUSIONS:

1. The cold ischemic time of the graft, has influence in the initial function of the kidneys but not in the evolution and duration of the graft.

2 . The hyperacute rejection has been overcome with the utilization of transgenic pigs. The graft failure was due to acute humoral rejection that was not aborted by the actual inmunosupressors.

3. It is necessary to develop new inmunosupression protocols, through new knowledge of their pharmacology and the physiology of the xenografts, and at the same time it is important to avoid the potential risk of transmission of animal infections.

KEY WORDS: Xenotrasplant. Baboon. Pig. Kidney. 
$\mathrm{E}$ xenotrasplante de órganos de cerdo es una de las esperanzas para aliviar la falta de órganos humanos para el trasplante. La disponibilidad de cerdos con distintos tipos de modificaciones genéticas creó grandes expectativas sobre una pronta utilización clínica de los mismos. Sin embargo, aunque los estudios experimentales preclínicos con el riñón han alcanzado supervivencias prolongadas, éstas son insuficientes para dar el paso a la fase clínica. Es necesario mejorar aspectos técnicos, profundizar en el conocimiento de los mecanismos inmunológicos del rechazo y disponer de protocolos inmunosupresores más eficaces y menos tóxicos para que los estudios clínicos puedan ser una realidad.

El rechazo hiperagudo con destrucción del órgano de forma inmediata, habitual en el trasplante de órganos entre especies distantes filogenéticamente, puede en la actualidad ser evitado mediante el trasplante de órganos de cerdos transgénicos. Sin embargo, la aparición de un posterior rechazo humoral agudo (RHA) también llamado rechazo vascular agudo (RVA) o xenorrechazo agudo retardado, da lugar al fracaso del xenotrasplante. La utilización de distintas pautas de inmunosupresión han conseguido retrasar de forma significativa este rechazo, pero no lo previenen de forma sistemática.

En este trabajo exponemos nuestra experiencia de xenotrasplante renal en babuino con órganos de cerdo transgénico para la proteína reguladora del complemento humano DAF (hDAF), realizada entre los años 2000-2003, utilizando distintos protocolos inmunosupresores. Así mismo, se revisa el estado actual del xenotrasplante de órganos de cerdo.

\section{MATERIAL Y MÉTODOS}

La experiencia se realiza en la Unidad de Cirugía Experimental (no $15002 \mathrm{AE}$ ) del Hospital Universitario Juan Canalejo y los animales son tratados siguiendo la normativa europea.

\section{Animales}

Durante el período 2000-2003 se han practicado 20 xenotrasplantes renales de cerdo transgénico hDAF (donante) a babuino (receptor). El peso de los cerdos osciló entre 11.400 y $75 \mathrm{~kg}$ y el de los babuinos entre 10 y $26.500 \mathrm{~kg}$. El peso del xenoinjerto, riñón del cerdo, osciló entre 39 y 160 gr.
Técnica quirúrgica en el cerdo

Los animales permanecen en ayunas desde 8$12 \mathrm{~h}$, antes de la intervención. La sedación e inducción anestésica se realiza con Guetamina y Medetomidina. La anestesia se efectúa con Sevoforane, manteniendo la analgesia con Fentanilo y relajación muscular con Atracurio. Se administra fluidoterapia a la que se añade antes de la extracción Manitol, Alprostadilo y Heparina.

La extracción de los riñones se realiza a través de incisión media transperitoneal (Fig. 1). Una vez liberados se extraen ambos riñones, seleccionando el que va a ser trasplantado en base a la anatomía del pedículo vascular. El otro se utilizará para estudios anatomopatológicos básicos y comparativos. Se perfunde con Eurocollins y se mantiene en frío hasta ser trasplantado. Finalmente se realiza eutanasia al cerdo mediante profundización del plano anestésico y administración de cloruro potásico.

Antes de implantar el xenoinjerto, es pesado y medido. Estos datos son importantes para el seguimiento ecográfico y valoración final del injerto.

\section{Técnica quirúrgica en el babuino}

Se realiza la misma técnica anestésica. A través de incisión de laparotomía media transperitoneal se libera arteria aorta y vena cava. Posteriormente se realiza el trasplante anastomosando arteria renal a aorta y vena renal a cava (Fig. 2). El riñón queda ubicado en situación retroperitoneal y el uréter se implanta en vejiga según técnica Leadbetter-Politano. Al terminar el trasplante se realiza nefrectomía bilateral de los riñones propios y finalmente biopsia del riñón trasplantado.

\section{Variantes técnicas}

En cuatro casos, una vez extraído el riñón y conservado en suero con hielo, se realiza la cirugía en el receptor, implantándolo posteriormente. El tiempo de isquemia fría osciló entre 85 y 165 minutos, media de 124 minutos (Técnica A).

En otros 16 casos se realiza la liberación del riñón sin extraerlo, posponiéndose ésta hasta estar preparado el campo quirúrgico del receptor. El tiempo de isquemia fría oscila entre 55 y 80 minutos, media 70 minutos (Técnica B). 

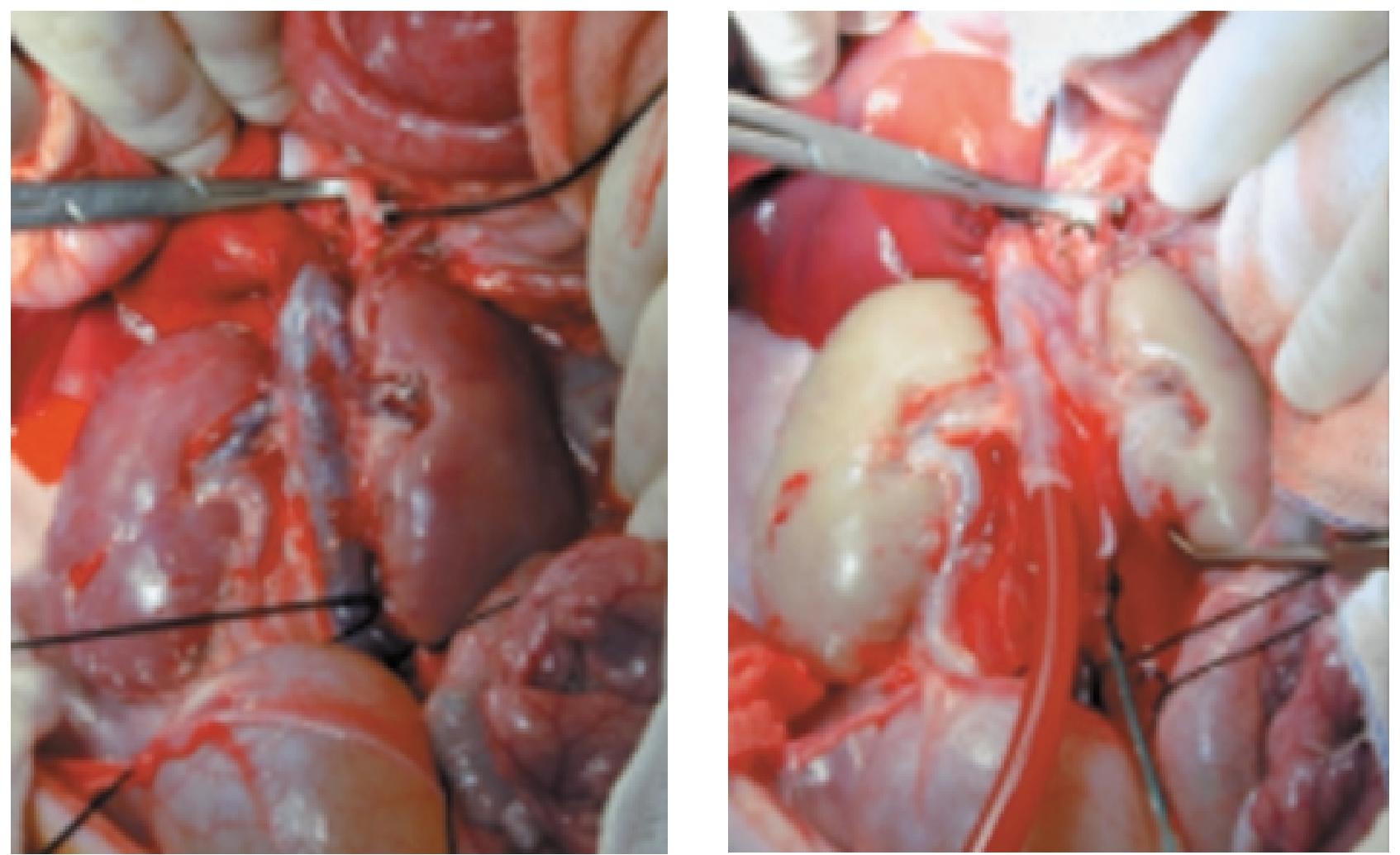

FIGURA 1. A) Preparación in situ de los riñones. B) Riñones con perfusión fria in situ.
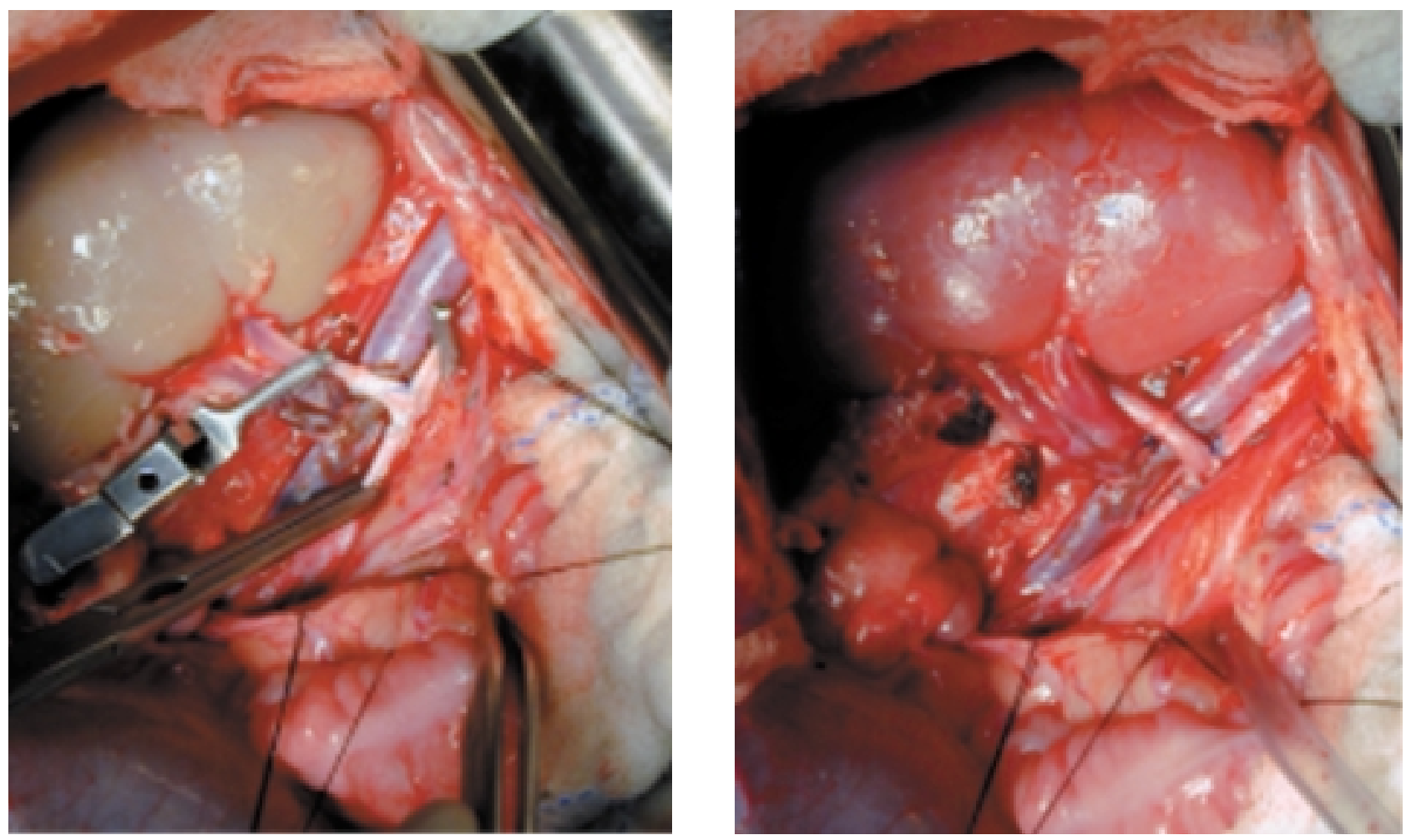

FIGURA 2. Xenotrasplante. A) Riñón trasplantado isquémico. B) Riñón trasplantado con circulación reestablecida. 
Por otra parte en los 13 primeros trasplantes se realiza primero la anastomosis venosa y posteriormente la arterial (VA). En los otros 7 se hace al revés, primero la anastomosis arterial y después la venosa $(\mathrm{AV})$.

\section{Control post-operatorio}

Los babuinos se mantienen aislados y a temperatura controlada, con monitorización de las constantes vitales administrándose sueroterapia y realizándose cuidados generales que incluyen analgesia con Bupremorfina y antibioterapia con Cefotaxima. Se realizan estudios analíticos de Hematología y Bioquímica cada 24-48 h, y estudios inmunológicos periódicos [nivel de anticuerpos anti-galactosa $\alpha$ 1-3 galactosa ( $\alpha \mathrm{Gal}$ ) IgM e IgG y anticuerpos hemolíticos porcinos (APHA)], así como ecografía protocolizada y en caso de complicaciones en la evolución. Los animales son eutanasiados cuando se considera que el fracaso renal es irreversible (Creatinina 8-9 mg/dl) o su estado general está irreversiblemente comprometido por complicaciones, toxicidad, etc. Dado que algunos estudios han sugerido una potencial ineficacia de la eritropoyetina de cerdo para sustentar la eritropoyesis en babuinos, los receptores recibieron eritropoyetina humana después del trasplante, así como transfusiones sanguíneas de otro babuino cuando estuvieron clínicamente indicadas.

\section{Inmunosupresión}

Todos los receptores recibieron GAS 914 sc 1 $\mathrm{mg} / \mathrm{kl} / 72 \mathrm{~h}$ desde el día $-17 \mathrm{al}-5 \mathrm{y} 1 \mathrm{mg} / \mathrm{kl} / 24$ $\mathrm{h}$ desde el día -4 al 0 y $1 \mathrm{mg} / \mathrm{kl} / 12 \mathrm{~h}$, posteriormente. El GAS 914 es una polilisina que lleva ensamblado el azúcar Galactosa $\alpha$ 1-3 Galactosa $(\alpha \mathrm{Gal})$, molécula que constituye la diana contra la que se dirigen los anticuerpos naturales antiporcinos de humanos y primates no humanos. El tratamiento con GAS 914 ha demostrado una depleción continuada de los anticuerpos anti$\alpha$ Gal (Fig. 3).

Se han utilizado cuatro protocolos de inmunosupresión: A) Inducción con Ciclofosfamida (CyP) en dosis de $40 \mathrm{mg} / \mathrm{kg}$ el día -1 y $20 \mathrm{mg} / \mathrm{kg}$ los días 0,2 y 4 , con la última dosis ajustada al número de leucocitos totales en sangre periférica (limite inferior $2.000 / \mathrm{mm}^{3}$ ); Ciclosporina (CyA) iniciada el día - 1 en dosis de $100 \mathrm{mg} / \mathrm{kg} / 12$ horas y ajustada después del trasplante para mantener unos niveles valle entre 1.000 y $1.500 \eta \mathrm{g} / \mathrm{ml}$,

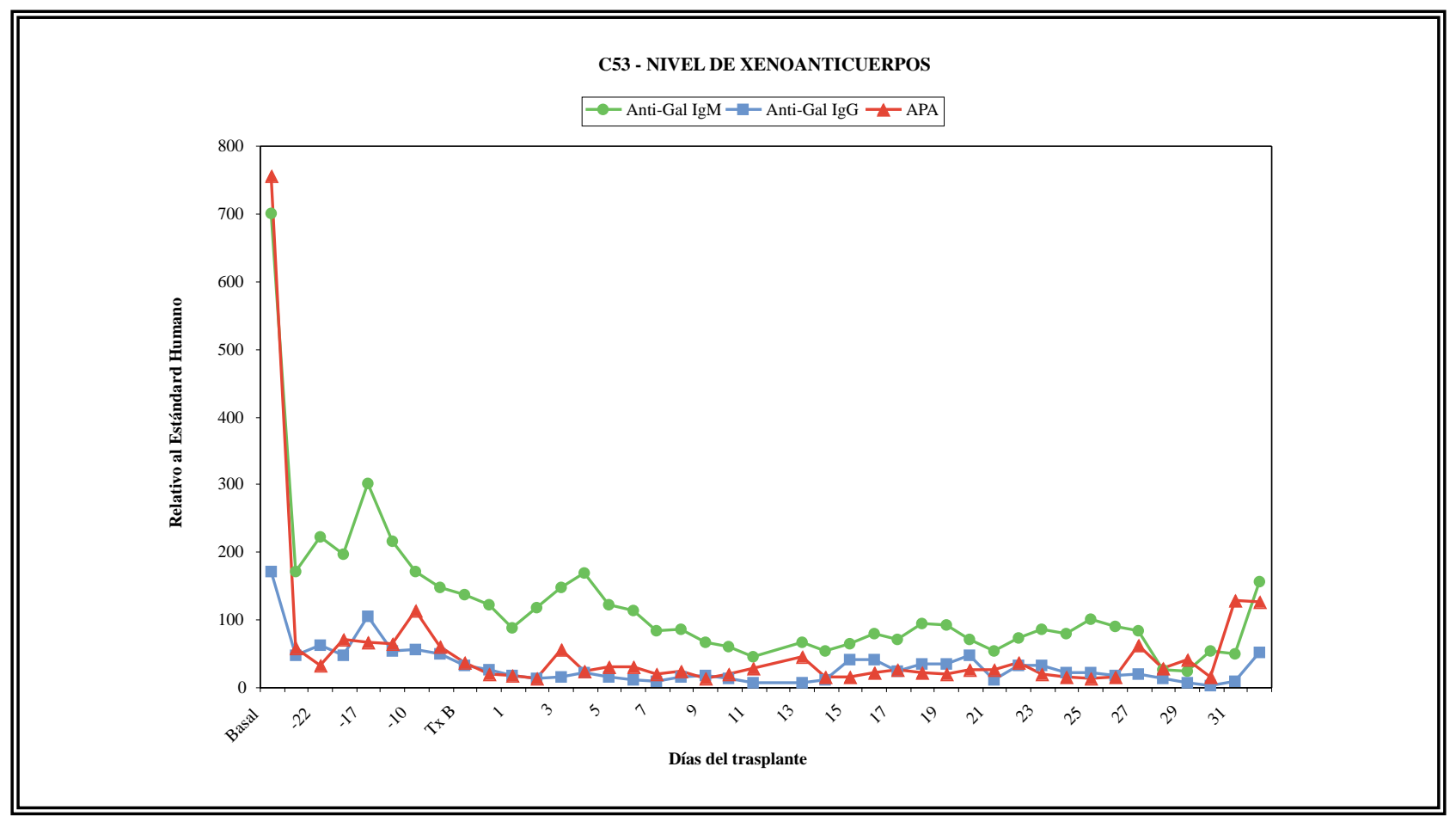

FIGURA 3. Gráfica de la evolución de los xenoanticuerpos en supervivencia de un mes. 
Micofenolato sódico (MNa) (Novartis Pharma, A.G., Basilea, Suiza) desde el día - 1 a una dosis de $35 \mathrm{mg} / \mathrm{kg} / 12$ horas y corticoesteroides 1 $\mathrm{mg} / \mathrm{kg}$ los días 0,1 y 2 , reduciéndose posteriormente $0,05 \mathrm{mg} / \mathrm{kg} /$ día hasta alcanzar una dosis de mantenimiento de $0,2 \mathrm{mg} / \mathrm{kg}(\mathrm{n}=10)$. B) CyP para la inducción, CyA y corticoesteroides a las dosis utilizadas en el protocolo A y FTY 720 e.v. (Novartis Pharma, A.G., Basilea, Suiza) 0,3-1 $\mathrm{mg} / \mathrm{kg} /$ día desde el día $-1 \quad(\mathrm{n}=3)$. C) Basiliximab (Bas) $10 \mathrm{mg} / \mathrm{kg}$ los días 0 y 4, y CyA, FTY 720 y corticoesteroides a las dosis anteriormente descritas (n=3). D) Basiliximab, FTY 720, y corticoesteroides a las dosis mismas previamente referidas y Everolimus (RAD), s.c, 0,075 mg/kg/día $(n=4)$.

\section{Histopatología}

Se tomaron muestras del riñón porcino trasplantado antes de la reperfusión, 1/2 hora después y en el momento del fracaso funcional del injerto (tomándose en este caso muestras renales del polo superior, polo inferior, cortical renal, unión cortico-medular, uréter y anastomosis arterial). Asimismo se estudió el riñón contralateral del cerdo en el momento del trasplante para diferenciar las lesiones previas de las adquiridas. Finalmente, a todos los babuinos se les realizó tras el fallecimiento o eutanasia una autopsia completa.

El material histológico fue fijado en formaldehído al $10 \%$ e incluido en parafina, realizándose secciones finas de menos de 3 micras de espesor, que se tiñeron con hematoxilina-eosina, PAS, plata-metenamina y tricrómico de Masson. Además se tomaron muestras para técnicas de inmunohistoquímica (inmunofluorescencia e inmunoperoxidasa) que se congelaron previamente en isopentano a $-50^{\circ} \mathrm{C}$, utilizando nitrógeno líquido. En las técnicas de inmunoperoxidasa se utilizaron anticuerpos contra IgM, IgG, C3, C4, y C5b9 y fibrina; y en los estudios de inmunofluorescencia IgM, IgG, IgA, C3, C4 y fibrina.

\section{RESULTADOS}

La supervivencia de los xenoinjertos osciló entre 1 y 31 días. En 3 (15\%) casos los animales fueron eutanasiados dentro de las $48 \mathrm{~h}$ siguientes por complicaciones quirúrgicas vasculares.
Estas incluyeron una hemorragia arterial y dos trombosis venosas. Seis receptores (30\%) fueron sacrificados entre los días 2 y 7 por un fracaso renal causado por mecanismos no inmunológicos como veremos posteriormente. Finalmente, en 11 receptores (55\%) el xenoinjerto funcionó entre 8 y 31 días, fracasando en 9 de ellos (45\%) por un rechazo humoral, en dos (10\%) por una obstrucción ureteral y una enfermedad por citomegalovirus (CMV), respectivamente. Tres xenoinjertos presentaban una estenosis ureteral en el estudio necrópsico siendo en uno de ellos la causa del fracaso del injerto, y con un papel que se desconoce en los otros dos.

La Técnica A (4 casos) se asoció con tiempos de isquemia fría que oscilaron entre 85 y 165 minutos con una media de 124. Al reperfundir los riñones trasplantados, recobran coloración y consistencia normal en 1 caso (25\%), con producción de orina inmediata, correspondiendo al caso de menos tiempo de isquemia fría, $85 \mathrm{minu}-$ tos. En los otros tres la coloración inicial fue irregular, parcheada, con zonas bien perfundidas, alternas con otras de coloración azulada y con un inicio de la diuresis demorado. La Técnica B incluyó 16 xenotrasplantes con tiempos de isquemia fría entre 55 y 80 minutos, con una media de 70 . La reperfusión total fue buena en $11(68,7 \%)$ y la diuresis inmediata en $13(81,2 \%)$ casos. El aspecto de reperfusión deficiente, parcheada, ocurrió en 5 casos, tres de ellos con diuresis inmediata y dos retardada. Este comportamiento inicial diferente en relación con los tiempos de isquemia no tuvo significación en la evolución final del xenoinjerto.

En relación con las anastomosis vasculares, en los 13 que se realizó, primero anastomosis venosa y después arterial (VA), se produjeron tres complicaciones vasculares (hemorragia-trombosis). En el grupo de 7 en los que se realizó anastomosis arterial primero y venosa después (AV), no se produjo ninguna complicación vascular. La trombosis venosa y hemorragia arterial apareció asimismo en el grupo de riñones de menor peso (menos de 95 gr). Ninguno que excedió este peso presentó la complicación.

En relación con los estudios histopatológicos, hemos dividido los 20 casos estudiados en 3 grupos. Grupo 1: en este grupo hemos incluido los 3 
casos en los que el fracaso del injerto fue secundario a problemas técnicos (hemorragias y trombosis). Los xenoinjertos mostraban diferentes grados de necrosis tubular aguda (NTA) en el caso de la hemorragia y áreas de isquemia-infarto con hemorragia y congestión en la trombosis venosa, sin depósitos inmunológicos. Sólo se observaban depósitos focales de IgM en capilares en ausencia de depósitos de complemento. Grupo 2: está constituido por los 6 casos con fracaso del injerto en los primeros siete días post-trasplante, de causa desconocida, descartándose el rechazo vascular como responsable. En este grupo los cambios histológicos eran inespecíficos y consistentes en diferentes grados de NTA, con congestión en capilares peritubulares, sin que existan causas isquémicas $\mathrm{u}$ obstructivas evidentes que los justifiquen aunque uno de los xenoinjertos renales mostraba necrosis focal de la pared de una arteria de mediano calibre. Las técnicas de inmunohistoquímica, en este grupo sólo mostraron depósitos de IgM sin presencia de complemento. Grupo 3: todos los injertos incluidos en este grupo desarrollaron fracaso funcional del injerto entre los días 8 y 31 post-trasplante. En todos los casos existía afectación a nivel glomerular consistente en lesiones de tipo microangiopático, caracterizadas por intensa congestión capilar, ensanchamiento de membrana basal capilar glomerular, presencia de trombos y/o ensanchamiento mesangial. Los túbulos mostraban signos de necrosis tubular aguda en distintos grados, con descamación, cilindros hemáticos y/o granulosos. En algunos casos destacaba la presencia de hemorragia intersticial, necrosis y congestión capilar peritubular. El estudio inmunohistoquímico mostró, en todos los casos, depósitos de IgM, C3, C4 y C5b9 localizado preferentemente en los capilares peritubulares y/o glomerulares (Fig. 4). Los hallazgos histológicos e inmunohistoquímicos son compatibles con rechazo humoral agudo (RHA): grado II en 7 casos y III en 2. Por último, dos xenoinjertos fracasaron en los días 28 y 31 del trasplante por causas no inmunológicas. En el primero el estudio histopatológico del riñón mostró abundantes inclusiones intranucleares típicas de CMV con nefritis intersticial y formación de microabscesos en los túbulos renales. El segundo xenoinjerto renal fracasó a los 31 días como consecuencia de un cuadro obstructivo a nivel ureteral, no descartándose que existía al mismo tiempo un componente de rechazo humoral con cambios a nivel de la vasculatura ureteral.

La mediana de la supervivencia de los xenoinjertos fue: 7 días (rango 1-31) con el protocolo de inmunosupresión A; 8 días (rango 4-28) con el B; 8 días (rango 3-13) con el C y 9 días (rango 1-20) con el D, respectivamente. En los casos de mejor evolución y supervivencia más prolongada, los parámetros de la función renal (creatinina, urea) se normalizan en 3-4 días (Fig. 5).

La concentración de los anticuerpos antigalactosa $\alpha$ 1-3 Galactosa ( $\alpha \mathrm{Gal}$ ) IgM, IgG y hemolíticos porcinos (AHPA) al tiempo del trasplante fueron (media \pm SD) $134 \pm 70,85 \pm 78$ y $56 \pm 38$, respectivamente. No se observaron cambios al RHA en el nivel de los anticuerpos $\alpha$-Gal, IgM y IgG que fueron respectivamente $103 \pm 9$ y $38 \pm$ 49, respectivamente. Sin embargo el RHA fue asociado con un notable aumento de APHA en 4 casos $(676 \pm 582)$, mientras en otros 6 casos no se observan cambios $(34 \pm 12)$.

La anemia normocítica, normocrómica y la hipoalbuminemia fueron, en mayor o menor grado, habituales en todos los babuinos trasplantados (Figs. 6 y 7 ).

\section{DISCUSIÓN}

El xenotrasplante de órganos no es una idea nueva. Se realizó con órganos de primates no humanos, en humanos (xenotrasplante concordante) en la década de los 60, con éxitos considerables especialmente en el trasplante renal ${ }^{1}$. Los primates humanos y no humanos pertenecen al mismo orden zoológico por lo que el trasplante de órganos entre ambas especies no comporta rechazo hiperagudo. Por múltiples razones (éticas, transmisión de enfermedades, dificultad de procreación en cautividad, etc.) se ha descartado el trasplante con estos primates y se ha elegido el cerdo como donante ideal.

Los órganos de cerdo no modificado, trasplantados en primate no humano (xenotrasplante discordante), son rápidamente destruidos por el rechazo hiperagudo. Esto tiene lugar porque los xenoanticuerpos naturales o preformados se depositan en el endotelio del injerto después de la 

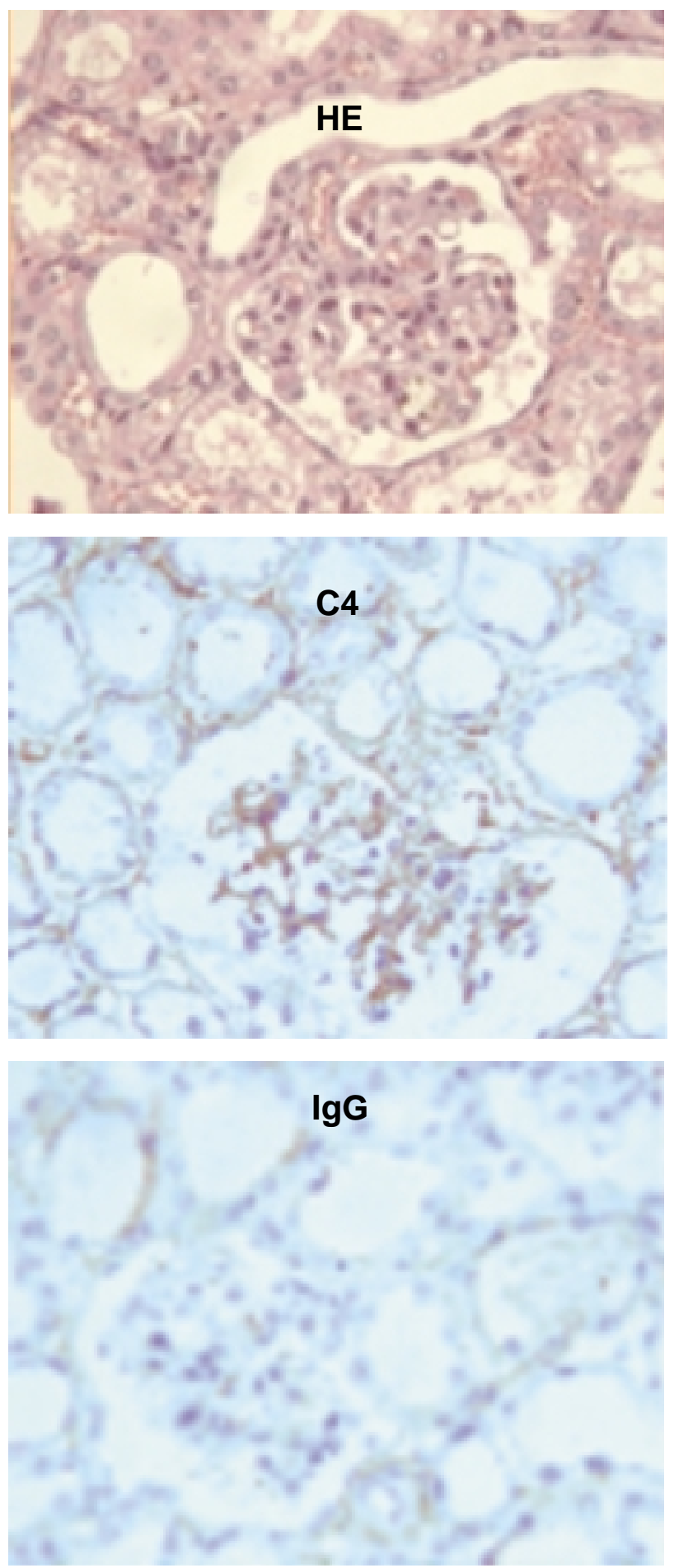
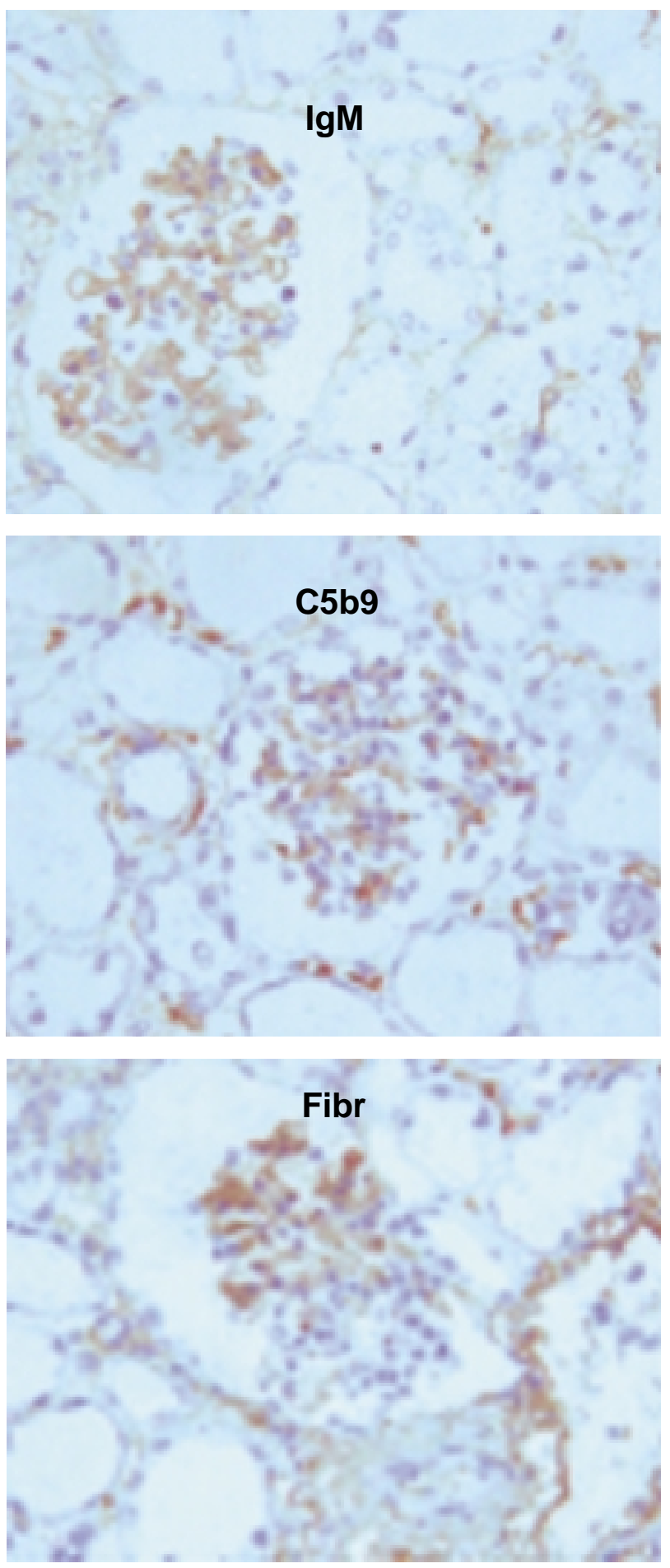

FIGURA 4. Rechazo Humoral Agudo. Signos de necrosis tubular aguda con vacuolización citoplasmática del epitelio tubular. Depósitos lineales de immunocomplejos (IgG, IgM), fracciones de complemento (C4, C5b-9, fibrina) en vasos glomerulares y capilares del intersticio renal, con técnica de immunoperoxidasa.

revascularización del órgano, activando el complemento y la coagulación, y dando como resultado un daño irreversible en pocos minutos del endotelio, con trombosis y oclusión vascular².
Los tratamientos inmunosupresores eficaces para inhibir la producción de anticuerpos inducidos no lo son para neutralizar los anticuerpos naturales ${ }^{3,4}$, de ahí que la primera barrera que 
debía vencer el xenotrasplante de órganos de cerdo era el rechazo hiperagudo, semejante al rechazo que tiene lugar cuando se realiza un trasplante entre grupos sanguíneos incompatibles. De la misma manera que un individuo del grupo A tiene anticuerpos contra el grupo B sin haber tenido contacto con este grupo sanguíneo, todos los humanos tenemos anticuerpos contra los antígenos del cerdo.

Los anticuerpos humanos capaces de fijar el complemento y producir el rechazo hiperagudo son esencialmente IgM y en menor proporción IgG e identifican una sola estructura: el disacárido, galactosa, $\alpha 1-3$, galactosa $(\alpha \mathrm{Gal})^{5}$. Este disacárido se encuentra presenta en las células de todos los mamíferos inferiores y monos del nuevo mundo, en los que sustituye a los azúcares responsables de los grupos sanguíneos $\mathrm{ABO}$, ya que poseen una enzima, la $\alpha 1-3$ galactosil transferasa que determina la producción de $\alpha \mathrm{Gal}^{6}$.

Los humanos, primates y monos del viejo mundo, tienen el gen responsable de la síntesis de la enzima inactivado, expresando en todas sus células los azúcares que caracterizan los grupos $\mathrm{ABO}$ y presentan los anticuerpos naturales contra $\alpha \mathrm{Gal}$. Las técnicas para neutralizar o eliminar los xenoanticuerpos, como plasmaféresis o inmunoadsorción, sólo lo hacen de forma transitoria, reapareciendo en un corto espacio de tiempo tras la supresión del procedimiento ${ }^{7}$.

Una forma más específica para evitar la activación del complemento ha sido la producción de cerdos transgénicos, que expresan en la membrana de sus células las proteínas reguladores del complemento humano, DAF, CD59, MCP o diversas combinaciones de las mismas ${ }^{8,9}$. Con los órganos de estos cerdos se evita el rechazo hiperagudo en la mayoría de las ocasiones persistiendo en otras ocasiones por causas no aclaradas ${ }^{10}$. En la experiencia llevada a cabo por el grupo de Cambridge en 102 trasplantes de riñón de cerdo transgénico hDAF-babuino no se produjo rechazo hiperagudo en ninguno, sin embargo en 41 trasplantes de corazón, se observó rechazo hiperagudo en el $7 \%{ }^{11}$. Esto sugiere que los factores responsables del rechazo hiperagudo están en relación con el tipo de órgano trasplantado. Hasta que punto esto refleja una diferente expresión de las proteínas humanas reguladoras del complemento entre los distintos órganos trasplantados, permanece por dilucidar.

La prevención habitual del rechazo hiperagudo representa un avance fundamental para poder trasplantar algún día órgano de cerdo en humanos, sin embargo no ha sido la solución definitiva como inicialmente se pensó. Cuando esta reacción no tiene lugar aparece posteriormente un RHA, que es la causa más frecuente del fracaso de los cerdos transgénicos para las proteínas reguladoras del complemento humano.

En el caso particular del riñón, la presencia de lesiones de tipo microangiopático a nivel glomerular, edema intersticial, signos de necrosis tubular aguda y congestión capilar, son datos histológicos no específicos pero muy sugerentes de lesión endotelial de la microcirculación renal secundaria a rechazo humoral ${ }^{12}$. El rechazo humoral es un diagnóstico no siempre factible, incluso en el trasplante humano, debido a la dificultad de su diagnóstico ante la ausencia de marcadores específicos. Lesiones sugestivas de rechazo humoral consistentes en microangiopatía glomerular, intensa congestión capilar y presencia de trombos estuvieron presentes en el Grupo 3. La confirmación del diagnóstico de rechazo humoral se realizó por la existencia de depósitos variable de IgM, IgG, C3, C4, C5b-9 y fibrina, que indican activación del complemento y coagulación como consecuencia del depósito de anticuerpos en el endotelio del órgano trasplantado.

Colvin et al. ${ }^{12}$ describen tres grados de RHA según la intensidad de los cambios histológicos. Así mismo, establecen la cronología histológica, indicando que la primera semana postrasplante las alteraciones histológicas son mínimas con depósitos focales de IgM, IgG y C3 y que después de los primeros 7 días es cuando empiezan a observarse signos histológicos sugestivos de rechazo humoral agudo. Nuestros resultados confirman esta cronología y demuestran que los mismos pueden tener lugar en el xenoinjerto, sin que existan cambios en los niveles de anticuerpos detectados en la sangre en más de la mitad de los casos. Esto sugiere que estos anticuerpos se depositan en el xenoinjerto renal, y sólo tras saturar la diana de los mismos en el órgano, son 
detectados en la circulación. En consecuencia, los tratamientos deben dirigirse a la prevención del depósito de anticuerpos, ya que una vez estos son detectados en la sangre es muy posible que exista ya un daño significativo del xenoinjerto.

Los cambios inespecíficos, que observamos en el Grupo 2 de nuestros casos, pueden ser debidos a distintos factores. Por un lado podría corresponder a un estadio inicial de un rechazo humoral agudo, ya que como se comentó con anterioridad, en los primeros días postrasplantes los cambios histológicos son mínimos y/o inexistentes. Además algunos autores no consideran necesarios los depósitos de complemento para establecer el diagnóstico de rechazo humoral ${ }^{13}$. Sin embargo, lo más posible es que nos encontremos ante factores no inmunológicos (medicamentos, hipotensión, isquemia) que de forma individual o al combinarse varios de ellos, dan lugar a una NTA, que sería potencialmente reversible si pudiéramos realizar diálisis temporalmente.

La elevada frecuencia del RVA como causa del fracaso de los órganos de cerdo transgénico para las proteínas humanas reguladoras del complemento, en primates no humano, ha convertido la prevención/tratamiento del mismo en el objetivo más importante del xenotrasplante. En nuestro estudio se han utilizado cuatro protocolos de inmunosupresión, que no han mostrado diferencias significativas en la supervivencia de los xenoinjertos, incorporando todos la utilización de GAS 914. Esta molécula consiste en una polilisina que lleva ancladas moléculas de $\alpha$-Gal, lo que permite neutralizar de forma continua y específica, antes y después del trasplante los anticuerpos $\alpha$-Gal ${ }^{14}$. Sin embargo, su utilización con la idea de prevenir el RVA no ha dado el resultado esperado. Resultados similares han sido obtenidos por otros autores. Zhong et al. ${ }^{15}$, utilizando un régimen inmunosupresor que incluía CyA, CyP, RAD y Metilprednisona, obtuvo una supervivencia de $18,5+/-8$ días. Con este mismo protocolo asociando GAS 914 no mejoran los resultados globales de supervivencia, aunque consigue una supervivencia máxima de 40 días con menor intensidad de las lesiones en los xenoinjertos. La razón es probablemente que aunque inicialmente se consideraba que los anticuerpos responsables del RVA eran también mayoritariamente anti- $\alpha$-Gal, éstos reconocen otras estructuras, y no pueden ser neutralizados por el GAS 914.

La CyP fue incluida desde un principio en los protocolos de inmunosupresión en el xenotrasplante de órganos de cerdo transgénico en primates no humanos, ya que es el medicamento más potente conocido hasta el momento para inhibir la producción de anticuerpos. Nuestros resultados confirman esta eficacia, ya que el grupo A, que combina CyP en inducción, junto con CyA, MNa y corticoesteroides para mantenimiento, es el que demuestra una menor incidencia de RVA. Sin embargo, también demuestra los importantes efectos secundarios que comporta este protocolo, ya que la mayoría de xenoinjertos fracasaron por causas no inmunológicas. Estos resultados son similares a los obtenidos por Cozzi et al. ${ }^{16}$ en los que la sustitución de la administración continua de CyP por Micofenolato Mofetil (mismo principio activo que el Mna), y una inducción perioperatoria de 4 dosis CyP, alcanza una máxima supervivencia de 51 días, con media de 21 , aunque el grado de severidad de las lesiones de RVA fue aparentemente menor. Este régimen terapéutico, inducción con CyP y mantenimiento de la inmunosupresión con CyA y Micofenolato, ha permitido alcanzar 90 días de supervivencia. Sin embargo, la causa del fracaso renal fue un RVA, lo que indica que puede aparecer incluso tras periodos prolongados de supervivencia del xenoinjerto ${ }^{17}$.

La utilización de agentes monoclonales frente al receptor de interleuquina 2 (IL-2) como el Basiliximab; el monoclonal anti CD-20, Rituximab, como sustituto de la CyD, tampoco han mejorado los resultados, logrando supervivencia máxima de 26 días de los xenoinjertos renales en babuino ${ }^{18}$, al igual que ocurrió en nuestro estudio. De forma similar, los anticuerpos policlonales tampoco han permitido un avance significativo en la prevención del RVA. Ghanekar ${ }^{19}$ et al. utilizaron cerdos transgénicos, GAS 914, CyP, RAD, suero antitimocítico (RATS) y RAD o RATS solamente. La supervivencia no varió estadísticamente (entre 3 y 4 semanas) y los animales fallecieron por fracaso renal tras rechazo humoral o complicaciones en relación con la inmunosupresión. A pesar de los resultados, los autores sugieren que la utilización de RATS mejora el RVA. 


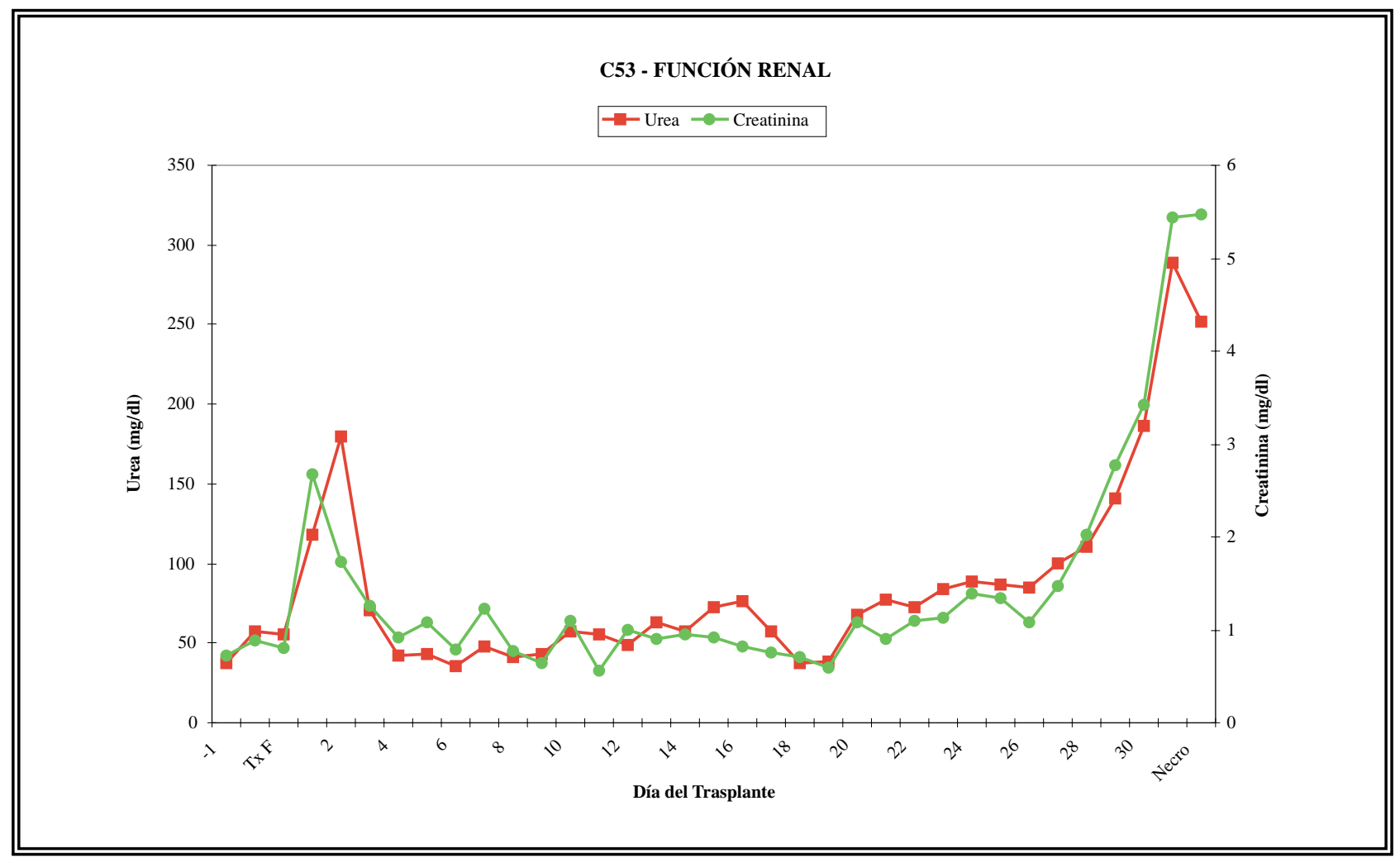

FIGURA 5. Gráfica de la evolución de la función renal, Creatinina y Urea, en supervivencia de 1 mes.

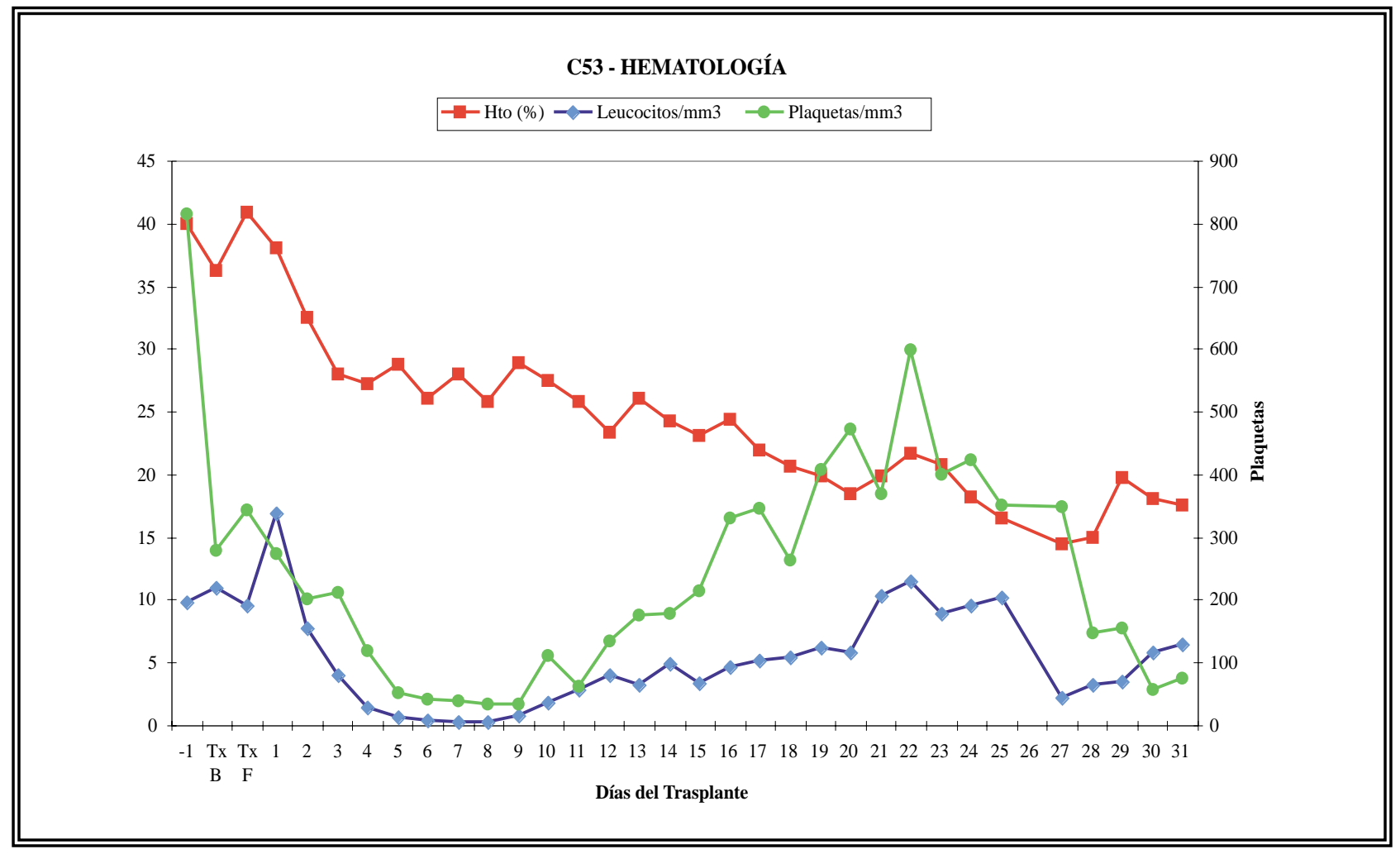

FIGURA 6. Gráficas de la evolución del Hematocrito, Leucocitos y Plaquetas en supervivencia de 1 mes. 


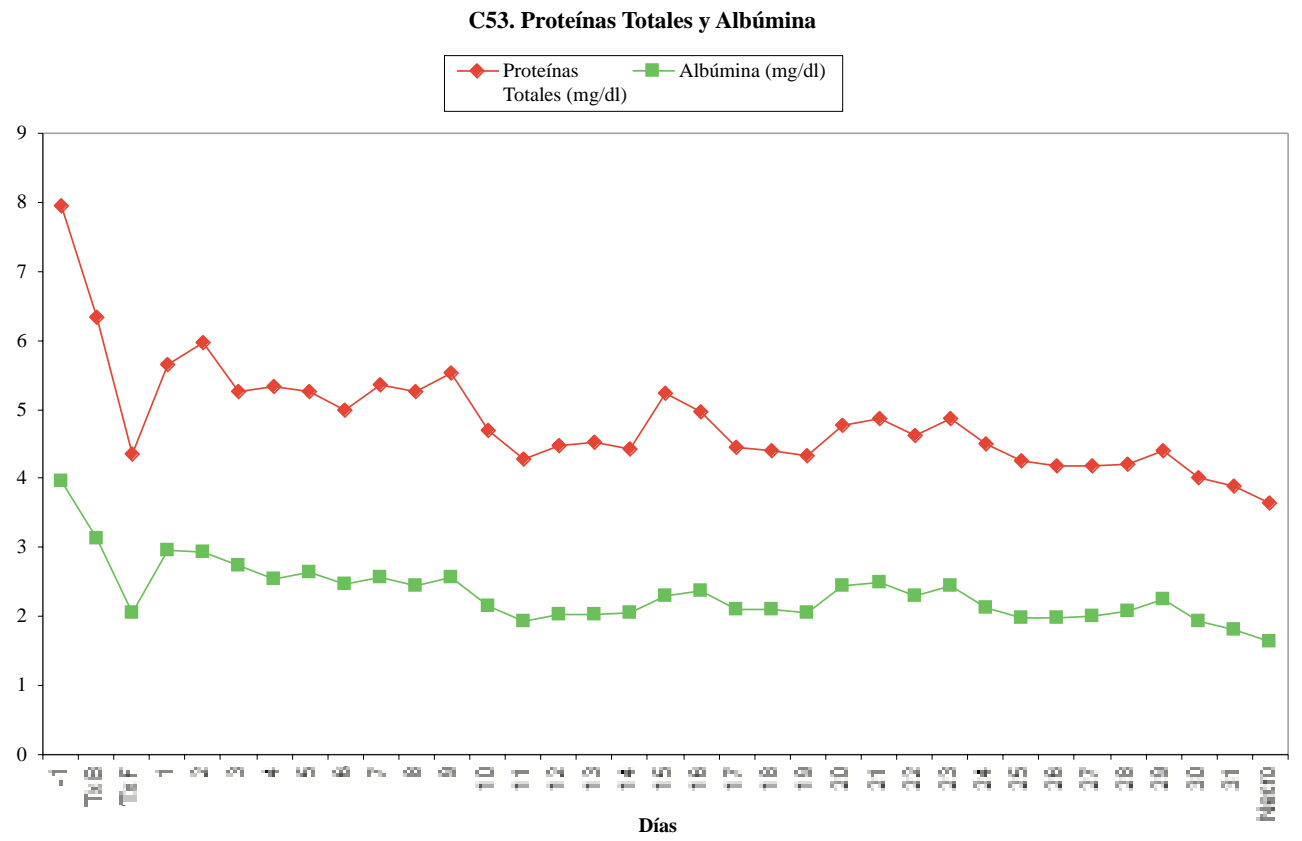

FIGURA 7. Gráficas de la evolución de las proteinas totales y albúmina en supervivencia de 1 mes.

Otras técnicas como la esplenectomía, que ha sido empleada con éxito en trasplante renal humano $\mathrm{ABO}$ incompatible ${ }^{20}$, también se han empleado en el xenotrasplante de cerdo-hDAFbabuino junto con tratamiento con CyP, CyA y esteroides logrando larga supervivencia ${ }^{22}$. En 4 de 9 animales más de 50 días, unos de ellos 78 . De todas formas el estudio anatomopatológico mostró lesiones de RVA grado III en todos los riñones porcinos, excepto en el de mayor duración, que fue grado I. El Cl-INH, inhibidor específico del complemento también ha sido investigado para prevenir el RVA, asociado a regímenes clásicos de inmunosupresión (CyP, CyA). La eficacia se evidenció reduciéndose significativamente los niveles de C3a y sC 5b-9 a la vez que recuperación funcional del xenoinjerto, logrando supervivencia máxima de 68 días ${ }^{23,24}$. Sin embargo, el RVA continuó siendo la causa más frecuente de fracaso de los xenoinjertos.

Estrategia diferente de la inmunosupresión para superar la barrera del RVA, ha sido la inducción de tolerancia mediante trasplante de médula ósea ${ }^{24}$, trasplante de bazo ${ }^{25}$, o timo ${ }^{26}$. En esta última e interesante experiencia se trasplan- ta el compuesto timo-riñón preparado previamente (40-80 días antes) mediante la implantación de tejido tímico debajo de la cápsula renal. El trasplante del injerto timo-riñón en modelo cerdo hDAF-babuino asociando inmunosupresión (GAS, Micofenolato, Globulina Antitimocítica, Ciclofosfamida, CD $40 \mathrm{~L}$, veneno de Cobra) ha conseguido el récord actual de supervivencia 229 días.

La búsqueda de un protocolo inmunosupresor o estrategia terapéutica que permita controlar los anticuerpos, aparentemente no anti- $\alpha \mathrm{Gal}$, responsables del RVA de los xenoinjertos porcinos transgénicos para las proteínas reguladoras del complemento humano, es en este momento el reto más importante para el xenotrasplante de órgano.

Las alteraciones de la coagulación se han descrito frecuentemente en el xenotrasplante de órganos porcinos. La máxima expresión es la coagulación intravascular diseminada que aparece como consecuencia de la microangiopatía trombótica que se asocia al rechazo del xenoinjerto. Sin embargo, también se han descrito alteraciones de la coagulación en ausencia de rechazo, por lo que éstas parecen poder tener distintos 
orígenes. En este sentido se han realizado experiencias, con el objetivo de impedir la activación de la coagulación, utilizando diferentes productos: Ajoene y Dipiridamol ${ }^{27}$ para impedir la agregación plaquetaria, y Hirudine $^{28}$ o Antibrombina III $^{29}$ como anticoagulantes. Los resultados obtenidos hasta el momento sugieren que la combinación de tratamientos anticoagulantes a los protocolos de inmunosupresión puede mejorar los resultados del xenotrasplante, aunque no de forma sustancial.

En el aspecto técnico, en nuestra experiencia, reseñamos que los riñones de cerdo son especialmente susceptibles a desarrollar vasoespasmo en relación con el manejo y tiempos de preservación en frío, siendo preciso, para lograr una rápida diuresis disminuirlo al máximo, por debajo de 85 minutos $^{30}$. E. Cozzi ${ }^{21}$, autor de gran experiencia en xenotrasplante, con tiempos de isquemia entre 95 y 241 minutos refiere que los injertos presentan muy pobre función inicial, produciendo entre $0 \mathrm{y}$ $11 \mathrm{ml}$ de orina en las primeras $24 \mathrm{~h}$, interpretándolo en relación con elementos técnicos y eventos inmunológicos precoces. Sin embargo, al igual que ocurre en nuestra serie no presupone una mala evolución posterior del injerto.

Las complicaciones trombóticas venosas constituyen el mayor problema técnico de nuestra serie, y pueden estar en relación con el tamaño de los riñones ya que ocurrió en riñones por debajo de 95 gramos. Experiencia semejante la tenemos en el humano, pero es significativo que la anastomosis arteria primero y vena después (AV) evite en estos casos dicha complicación. La estenosis ureteral en el xenotrasplante de riñones porcinos, ha sido elevada, y atribuible al rechazo. Balan ${ }^{31}$ y colaboradores en el estudio anatomopatológico de estos uréteres encuentran signos de rechazo humoral agudo con fibrina intravascular, depósitos de C3 y C5 b-9 junto con necrosis fibrinoide, erosión mucosa difusa $y$ trombosis de vasos sanguíneos.

Un aspecto que ha preocupado particularmente en el xenotrasplante renal es la posibilidad de incompatibilidades fisiológicas y diferencias especie-específicas entre mamíferos, fruto de la especialización funcional que cada una de ellas ha desarrollado a lo largo de su evolución, y que son la expresión de múltiples diferencias genéticas. La mayoría de estas incompatibilidades son desconocidas en la actualidad. Esta situación puede dar lugar a que un xenoinjerto no sea tan eficaz como un aloinjerto, en su capacidad de compensar las diferentes funciones biológicas de un órgano crónicamente disfuncionante, aunque sí capaz de mantener la supervivencia del receptor a medio o largo plazo ${ }^{32}$.

En nuestra serie, dado que no se obtuvieron supervivencias a largo plazo, la mayoría de los hallazgos están en relación con la propia disfunción del injerto renal $\mathrm{u}$ otras complicaciones post-operatorias. Así se apreció la presencia de hipoalbuminemia, probablemente multifactorial, hiperfosfatemia y grados variables de hipocalcemia subclínica. No se observaron alteraciones sustanciales en el balance hidroelectrolítico o en el equilibrio ácido-base. El papel de la PTH, del calcitriol o de la $\mathrm{ADH}$ no está adecuadamente estudiado en estos modelos de trasplante.

La presencia de grados variables de anemia y trombopenia son habituales, esta última en relación con activación endotelial y trombosis capilar, así como por el efecto de algunas drogas mielodepresoras.

La anemia fue habitual, en general de tipo normocítico normocrómico lo que obligó al empleo rutinario de eritropoyetina humana (EPO). Esta anemia tiene un origen multifactorial en relación con sangrado post-quirúrgico, extracción de muestras sanguíneas, efecto tóxico de la inmunosupresión $^{33}$ pero también con resistencia a la eritropoyetina del cerdo $\mathrm{u}$ otro tipo de incompatibilidades entre cerdo y primate. En algunos casos, es evidente un componente hemolítico en relación con microangiopatía trombótica y rechazo vascular.

Uno de los aspectos más controvertidos al hablar de xenotrasplante es el riesgo de xenosis o xenozoonosis, términos acuñados para indicar aquellas infecciones transmitidas a través del trasplante de células, tejidos u órganos entre individuos de diferentes especies ${ }^{34}$, y por tanto una posibilidad real con este tipo de trasplantes. La situación se ve agravada por la necesidad de administrar una potente inmunosupresión, para evitar el rechazo del xenoinjerto, y todo ello en un contexto de limitada información clínica y bacteriológica. Esta situación ocurre, además, en un trasplante, que como el renal, no es vital para el paciente, que siempre tiene la opción de la diálisis. 
La principal preocupación actual radica en la posibilidad de transmisión de retrovirus endógenos porcinos (PERVs), que se conoce que pueden infectar células humanas in vitro ${ }^{35,36}$, con un potencial patogénico desconocido, no sólo para el receptor sino también para su entorno familiar y sanitario. La experiencia reciente con la pandemia originada por el HIV o en menor medida por la Encefalopatía Espongiforme Bovina, obligan a extremar la cautela. Datos preliminares acerca de la transmisión e infección por PERVs, son sin embargo esperanzadores ${ }^{37-39}$ y coherentes con la larga exposición de los humanos al cerdo durante miles de años. Sin embargo otros múltiples gérmenes pueden verse implicados.

Las investigaciones, en cualquier caso, deberán aclarar de forma suficiente los riesgos de xenozoonosis antes de que el xenotrasplante se convierta en una realidad viable. Los diversos enfoques para resolver este problema, son sin duda complementarios. La posición ética respecto a éste y otros temas relacionados ha sido fijada recientemente por la I.X.A. ${ }^{40}$ y también en nuestro país ${ }^{41}$.

En conclusión el xenotrasplante de órganos de cerdo en humanos puede ser una alternativa al déficit de órganos cadavéricos para el trasplante. La producción de cerdos transgénicos, que expresan los genes humanos de las proteínas reguladoras del complemento, ha permitido superar la barrera inmunológica del rechazo hiperagudo. Distintos protocolos de inmunosupresión logran supervivencias del riñón funcionante entre 1 y 3 meses pero habitualmente a costa de alta toxicidad. Para que el xenotrasplante pueda ser una realidad clínica es necesario progresar en el estudio inmunológico que nos permita prevenir y tratar el RVA, en el conocimiento funcional del injerto y en la evaluación del potencial riesgo de transmisión de infecciones a partir del mismo, algo que nuestra experiencia y la de otros sugiere que no tiene que ser un obstáculo para la realización del xenotrasplante con órganos porcinos.

Agradecimientos: Nuestro agradecimiento a la Fundación Juan Canalejo y la Fundación Barrié de la Maza, que apoyan y financian nuestros trabajos de Investigación en Xenotrasplante y al personal de la Unidad de Investigación por su dedicación.

\section{REFERENCIAS}

1. LAMBRIGTS D, SACHS DH, COOPER DKC.: Discordant organ xenotransplantation in primates. World experience and current status. Transplantation 1998; 66: 547-561.

2. PLATT JL, FISCHEL RJ, MATAS AJ, REIF SA, BOLMAN RM, BACH FH.: Immunopathology of hipercute xenograft rejection in a swine-to-primate model. Transplantation 1991; 52: 214-220.

3. LAMBRIGTS D, VAN CALSTER P, XU Y, AWWAN M, NEETHING FA, KOZLOWSKI T, FOLEY A, WATTS A, CHAE SJ, FISHMAN J, THALL AD, WHITE-SCHART ME, SACHS DH, COOPER DKC.: Pharmacologic and immunosuppressive therapy and extracorporeal immunoadsorption in the suppression of $\alpha \mathrm{Gal}$ antibodies. Xenotransplantation 1998; 5: 274-283.

4. MÁÑEZ R, BLANCO FJ, DÍAZ I, CENTENO A, LÓPEZ-PELÁEZ E, HERMIDA M, DAVIES H, KATOPODIS A.: Removal of bowel aerobic gram-negative bacteria is more effective tham immunosuppression with cyclophosphamide and steroids to decrease natural $\alpha$-Galactosyl IgG antibodies. Xenotransplantation 2001; 8: 15-23.

5. GALILI U, MACHER B, BUEHLER J, SHOHET SB. Human natural anti- $\alpha$ Gal-Galactosyl IgG. II The specific recognition of $\alpha \mathrm{Gal}(1-3)-$ linked galactose residues. J Exp Med 1985; 162: 573-582.

6. GALILI U, SHOHET SB, KOBRIN E, STULTS C, MACHER B.: Man, apes, and Old World monkeys differ fron other mammals in the expression of $\alpha \mathrm{Gal}$ epitopes on nucleated cell. $J$ Biol Chem 1988; 263: 17755-17762.

7. TANIGUCHI S, NEETHING FA, KORCHAGINA EY, BOVIN N, YE Y, KOBAYASHI T, NIEKRASZ, LI S, KOREN E, ORIOL R, COOPER DKC.: In vivo immunoadsorption of specific Gala13Gal colum. Transplantation 1996; 62: 1379-1384.

8. FODOR WL, WILLIAM BL, MATIS L, MADRI JA, ROLLINS S, KNIGHT JW, VELANDER W, SQUINTO SP.: Expression of a functional human complement inhibitor in a transgenic pig as a model for the prevention of xenogeneic hyperacute organ rejection. Proc Natl Acad Sci USA 1994; 91: 11153-11157.

9. COZZI E, WHITE KJ.: The generation of transgenic as potential organ donors for humans. Nat Med 1995; 1: 964-966.

10. BHATTI FN, ZAIDI A, SCHOMOECKEL M, COZZI E, CHAVEZ G, WALLWORK J, WHITE DJ.: Prolonged survival of hDAF transgenic pig kidneys in primates. Transplantation 1998; 65: 1584-1590.

11. SCHUURMAN HJ, PINO-CHAVEZ G, PHILLIPS MJ, THOMAS L, WHITE DJ, COZZI E.: Incidence of hiperacute rejection in pig-to-primate transplantation using organ from hDAF transgenic donors. Transplantation 2002; 15: 1146-1151.

12. SHIMIZU A, MEHAAN SM, KOZLOWSKI T, SABLISNSKI T, IERINO FL, COOPER DK, SACHS DH, COLVIN RB.: Acute humoral xenograft rejection: destruction of the microvascular capillary endothelium in pig-to-non humam primate renal grafts. Lab Invest 2000; 80: 815-830.

13. BÜHLER L, YAMADA K, KITAMURA H, ALWAYN PJ, BASKER M, APPELL HZ, COLVIN RB, WHITE-SHARF ME, SACHS DH, ROBSON SC, AWWAD M, COOPER DK.: Pig kidney transplantation in Baboons: Anti-Gal x 1-3 Gal IgM in associated with acute humoral xenograft rejection and disseminate intravascular coagulation. Transplantation 2001; 72: 1743-1752.

14. MÁÑEZ R, CENTENO A, LÓPEZ-PELÁEZ E, RUIZ DE VALBUENA C, JUFFE A, HOLMES B, DUTHALER R, KATOPODIS A.: GAS 914, a polylysine containing $\alpha \mathrm{Gal}$, prevents acute humoral rejection in $\mathrm{hDAF}$ pig to primate heterotopic heart xenotransplantation. Xenotransplantation 2001; 8 (suppl 1): 4.

15. ZHONG R, LUO Y, LEVY G, GARCÍA B, PHILLIPS J, YANG H, GHANEKAR A, COZZI E, KATOPODIS A, GRANT D.: GAS 914 $\alpha \mathrm{Gal}$ analoge ameliorates porcine kidney xenografts rejection in baboons. Libro Abstracs VI Congress Intern Xenotransplants. Assoc Chicago IL. USA 2001; nº 079. 
16. COZZI E, VIAL C, OSTLIE D, FARAH B, CHAVEZ G, SMITH KGC, BRADLEY JR, THIRU S, DAVIES HFS, WALLWORK J, WHITE DJG, GODDARD M, FRIEND PJ.: Maintenance triple immunosuppression with Cyclosporin mycophenolate sodium and steroids allows prolonged survival of primate recipients. Xenotrasplantation 2003; 10: 300-310.

17. DEDJA A, RIGOTTI P, BALDAN N, CADROBBI C, VANANZI C, CALABRESE F, IACOPETTI I, BUSETTO R, COZZI E, ANCONA E.: Long-term survival on non-splenectomized Cynomologus monkeys receiving $\mathrm{hDAF}$ porcine renal xenografts and a maintenance immunosuppression with cyclosporine A, mycophenolate sodium and steroids. Libro Abstracs VI Congress Intern Xenotransplants. Assoc Chicago IL. USA 2001; no 409.

18. BECKER Y, HULLETT D, FRIEDI A, HERRIN SO, USBORNE A, YRACHETA Y, ASCHENBRENNER J, SOLLINGER H.: Basiliximab and Rituximab increase survival in pig-to-baboon kidney xenotransplantation. Libro Abstracs VI Congress Intern Xenotransplants. Assoc Chicago IL. USA 2001; nำ 165.

19. GHANEKAR A, LAJOIE G, LUO Y, YANG H, CHOI J, GARCÍA B, COLE EH, GREIG PD, CATTRAL MS, PHILLIPS MJ, CARDELLA CJ, LEVY GA, XHONG R, GRANT DR.: Improvement in rejection of human decay accelerating factor transgenic pig-to primate renal xenografts with administration of rabbit antithymocyte serum. Xenotransplantation 2002; 74: 28-35.

20. ALEXANDRE GP, SQUIFFET JP, BRUYERE D. Splenectomy as a prerequisite for successful human $\mathrm{ABO}$-imcompatible renal transplantation. Transplant Proc 1985; 17: 138.

21. COZZI E, BHATTI F, SCHMOEAKEL M, CHAVEZ G, SMITH KGC, ZAIDI A, BRADLEY JR, THIRU S, GODDARD M, VIAL C, OSTLIE D, WALLWORK J, WHITE DJC, FRIEND PIJ.: Longterm survival of nonhuman primates receiving life-supporting transgenic porcine kidney xenografts. Xenotransplantation 2000; 70: 15-21.

22. VANGEROUW B, HECKER JJ, LORENZ R, LOSS M, PRXEMECK M, PPIAHR A, SCHMIDKO J, JALALI A, RUECKOLDT H, WINKLER M.: C1-inhibitor for treatment of acute vascular xenograft rejection in cynomologus recipients of hDAF transgenic porcine kidneys. Xenotransplantation 2001; 8: 266-272.

23. HECKER JM, LORENZ R, APPIAH R, VANGEROW R, LOSS M KUNZ R, SCHMIDKO J, MENGEL M, KLEMPNAVER J, PIEPENBROCK S, DICKNEITE G, NEIDHARCT, RUCKOLDT H, WINKLER M.: C1-inhibidor for prophilaxis of xenograft rejection after pig to cynomologus monkey kidney transplantation. Transplantation 2002; 15: 675-677.

24. ABE M, QI J, SYKES M, YANG YG.: Tolerance induction across a highly disparte xenogeneic barrier by bone marrow transplantation. Libro Abstracs VI Congress Intern Xenotransplants. Assoc Chicago IL. USA 2001; nº 145.

25. ZHANG H, LI Y, WANG K, MA Y.: The status of chimeric cells in a guman to pig spleen transplantation model. Libro Abstracs VI Congress Intern Xenotransplants. Assoc Chicago IL. USA 2001; no 322 .

26. BARTH RN, YAMAMOTO S, LAMATTINA JC, KAMAGAY N, KITAMURA H, VAGEFI FA, AWWAD M, COLVIN RB, COOPER DKC, SYKES M, SACHS SH, YAMADA K.: Xenogenic Thymokidney and Thymic tissue transplantation in a pig-tobaboon model: I evidence for pig-specific T-cell unresponsiveness. Transplantation 2003; 75: 1615-1624.

27. TERANISHI K, ROBSON S, ROMANO E, COOPER D, APITX R.: Suppression of baboon platelet aggregation in vitro and in vivo by the garlic derivate, ajoene. Libro Abstracs VI Congress Intern Xenotransplants. Assoc Chicago IL. USA 2001; $n^{\circ} 300$.

28. SCHELZIG H, VOGEL A, KRISCHER C, ABENDROTH A.: Role of recombinant hirudin in a pig-to-human lung transplantation model. Libro Abstracs VI Congress Intern Xenotransplants. Assoc Chicago IL. USA 2001; n 301.
29. COWAN P, AMINIAN A, BROWN A, FRANCIS D, GOCK H, GOODMAN D, SALVARIS E, SHINKEL T, STEWART A, D'APICE T.: Protective effects of recombinant human antithrombin III in pig-to-primate renal xenotransplantation. Libro Abstracs VI Congress Intern Xenotransplants. Assoc Chicago IL. USA 2001; no 077.

30. GONZÁLEZ MARTÍN M, VÁZQUEZ MARTUL E, LÓPEZ PELÁEZ E, CENTENO A, ALONSO A, GARCÍA BUITRÓN JM, REQUEJO I, MÁÑEZ R.: Non-immunologic causes of xenograft failure in hDAF pig-to-baboon kidney transplantation. Transplantation 2002; 74 (supp.): 357.

31. BALAN N, CALABRESE F, RIGOTTY P, CADROBBI R, DEDJA A, ISOLA M, LIDEO L, MICHIELAN F, COZZI E, ANCONA E.: Ureteral stenosis in hDAF pig-to-primate renal xenotransplantation: a phenomenon related to immunological events. Libro Abstracs VI Congress Intern Xenotransplants. Assoc Chicago IL. USA 2001; n⿳0 200.

32. STARZL TE, TZAKIS A, FUNG JJ, TODO S, DEMETRIS AJ, MAÑEZ $\mathrm{R}$ et al.: Prospects of clinical xenotransplantation. Transplant Proc 1994; 26: 1082-1088.

33. MARTORELL J.: Obstáculos y perspectivas del xenotrasplante. Transplantament 1998; 7 (diciembre): 2-3.

34. FISHMAN JA.: Xenosis and xenotransplantation: addressing the infectious risk posed by emerging technology. Kidney Int 1997; 51 (supp 58): S-41-S-45.

35. PATIENCE C, TAKEUCHI Y, WEISS RA.: Infection of human cells by an endogenous retrovirus of pigs. Nature Med 1997; 3: $282-286$.

36. BLUSCH JH, PATIENCE C, MARTIN V.: Pig endogenous retroviruses and xenotransplantation. Xenotransplantation 2002; 9: $242-251$.

37. SPECKE DJ, SCHUURMANN V, PATIENCE C, PLESKER R, COULIBALY C, KURTH R.: Porcine endogenous retroviruses (PERVs): latest update in non-human primate infection studies (Abstract). Xenotransplantation 2003; 10: 480.

38. DENNER J, IRGANG M, SAUER IM, KARLAS A, GERLACH JC, NEUHAUS P, KURTH R.: A new retrospective study on transmission of porcine endogenous retroviruses (PERVs) in patients treated with a bioreactor based on porcine liver cells (Abstract). Xenotransplantation 2003; 10: 496.

39. DOMÉNECH N, HERMIDA M, MOSCOSO I, DÍAZ T, MÁÑEZ R.: Lack of cross-species transmission of porcine endogenous retrovirus (PERV) in pig-to baboon organ xenotransplantation with persistent deplection of anti- $\alpha \mathrm{Gal}$ (Abstract). Xenotransplantation 2003; 10: 520.

40. SYKES M, D`APICE A, SANDVIN M (IXA Ethics Committee).: Position paper of the Ethics Committee of the International Xenotransplantation Association. Xenotransplantation 2003; 10: 194-203.

41. Xenotrasplante. Informe de la Subcomisión de Xenotrasplante de la Comisión Permanente de Trasplantes del Consejo Interterritorial del Sistema Nacional de Salud. Editorial Complutense S.A. Madrid, 1999.

Dr. M. González Martín

Servicio de Urología

Hospital Juan Canalejo

Xubias de Arriba, 84

15009 La Coruña

(Trabajo recibido el 15 diciembre de 2003) 